\title{
Evaluation of asymptomatic bacteruria management before and after antimicrobial stewardship program implementation: retrospective study
}

Ahlam Alghamdi ${ }^{1,2^{*}}$, Majid Almajid ${ }^{3}$, Raneem Alalawi ${ }^{4}$, Amjad Alganame $^{4}$, Shorooq Alanazi ${ }^{4}$, Ghaida Alghamdi $^{5}$, Salman Alharthi ${ }^{3}$ and Isra Alghamdi ${ }^{5}$

\begin{abstract}
Background: The Infectious Diseases Society of America (IDSA) recommends against screening for and/or treating asymptomatic bacteriuria (ASB). This study aims to evaluate the inappropriate use of antibiotics in ASB before and after Antimicrobial Stewardship Program (ASP) implementation and advance towards its appropriate use.

Method: We performed a retrospective study of patients diagnosed with ASB from 2016 to 2019 at a tertiary hospital in Saudi Arabia. This study included hospitalized patients $\geq 18$ years old who had a positive urine culture with no documented signs or symptoms of urinary tract infection We excluded pregnant women, solid organ transplant patients, patient on active chemotherapy, and patients about to undergo urological surgery.

Results: A total of 716 patients with a positive urine culture were screened. Among these, we identified 109 patients with ASB who were included in our study. The rate of inappropriate antibiotic use was $95 \%$ during the study period. The implementation of the ASP Program was associated with a significant reduction in the use of carbapenems $(P=0.04)$ and an increase in the use of cephalosporins $(P=0.01)$. However, overprescribing antimicrobial agents was a concern in both eras. Approximately $90 \%$ of the microorganisms identified were gramnegative bacteria. Of those, $38.7 \%$ were multidrug-resistant strains.
\end{abstract}

Conclusion: The urine culture order in ASB is considered relatively small number; however, it showed a high rate of the inappropriate use of antibiotics when there is an order of urine culture in both era. ASP ought to focus on targeting the ordering physician, promoting awareness and/or organizational interventions that appear to reduce the incidence of overtreatment.

Keywords: Antimicrobial agent, Asymptomatic bacteriuria, Urinary tract infection, Antimicrobial stewardship program

\footnotetext{
* Correspondence: ahaalghamdi@pnu.edu.sa

Infectious Disease Pharmacy Department, Security Forces Hospital where the work was done.

${ }^{1}$ Pharmacy Practice Department, Princess Nourah Bint Abdulrahman

University, Riyadh, Saudi Arabia

${ }^{2}$ Pharmacy Practice Department, King Abdullah bin AbdulAziz University

Hospital, Riyadh, Saudi Arabia

Full list of author information is available at the end of the article
}

(c) The Author(s). 2021 Open Access This article is licensed under a Creative Commons Attribution 4.0 International License, which permits use, sharing, adaptation, distribution and reproduction in any medium or format, as long as you give appropriate credit to the original author(s) and the source, provide a link to the Creative Commons licence, and indicate if changes were made. The images or other third party material in this article are included in the article's Creative Commons licence, unless indicated otherwise in a credit line to the material. If material is not included in the article's Creative Commons licence and your intended use is not permitted by statutory regulation or exceeds the permitted use, you will need to obtain permission directly from the copyright holder. To view a copy of this licence, visit http://creativecommons.org/licenses/by/4.0/ The Creative Commons Public Domain Dedication waiver (http://creativecommons.org/publicdomain/zero/1.0/) applies to the data made available in this article, unless otherwise stated in a credit line to the data. 


\section{Introduction}

Asymptomatic bacteriuria (ASB) refers to the isolation of $\geq 10^{\wedge} 5$ colony-forming units $[\mathrm{CFU}] / \mathrm{mL}$ or $\geq 10^{\wedge} 8$ CFU/L of bacteria from an appropriately collected urine specimen in an individual with no signs or symptoms of urinary tract infection [1, 2]. ASB is common, but its exact prevalence is highly variable. Patients with chronic indwelling catheters and spinal cord injuries have a very high prevalence of bacteriuria (100 and 50\%, respectively) compared with that among healthy premenopausal women (1\%) [1-3]. In 2019, IDSA recommended against screening for and/or treating ASB with antibiotics unless patients are undergoing endoscopic urologic procedures associated with mucosal trauma or are pregnant [1]. The inappropriate treatment of ASB has no positive impact on clinical outcomes and results in adverse events $[1,4$, 5]. In recent years, the overprescribing of antibiotics for ASB has contributed to an increasing number of health care-related problems in clinical practice. A prospective study found that overtreatment of ASB was responsible for $17 \%$ of prescribed antimicrobials [6]. In fact, overtreatment of ASB led to several adverse effects, such as increased prevalence of multidrug-resistant (MDR) organisms, increased rates of Clostridium difficile infection (CDI) and long hospitalizations, all of which factors increase the costs of health care [2, 7-9]. In addition, previous studies have shown that MDR organisms are frequently found in ASB patients, with a prevalence of $16 \%[4,5,7]$. These findings support the guideline recommendations against ASB treatment. ASB is a major concern worldwide, and few studies outline the types of antibiotics unnecessarily prescribed and the associated costs. The goal of our study was to evaluate the inappropriate use of antibiotics in ASB patients before and after the implementation of Antimicrobial Stewardship Program (ASP).

\section{Methods}

\section{Study setting}

We conducted a 4-year retrospective, descriptive study to determine the inappropriate use of antimicrobials in ASB patients at a tertiary hospital, 700-bed located in Riyadh, Saudi Arabia.

\section{Antimicrobial stewardship program implementation}

In 2018, ASP has been applied as one of the tools to fight microbial resistance and antimicrobial misuse. The aim was to focus on strategies that have most impact on decreasing antibiotics use and resistance. The ASP activities are perform by the stewardship team during the working hours (not weekend and after working hours). The main ASP activities include the following:
- Carbapenem restriction and prior authorization: restricted to infectious disease physicians; however, it can be given up to $24 \mathrm{~h}$ until ID team approve the continuation.

- Prospective audit and feedback (PAAF): The therapeutic interventions are not specific to ASB, but ASB cases were included and subjected to ASP. ASB cases interventions are through direct verbal communication with the prescriber and/or written communication in "Antimicrobial Stewardship Note) progress note.

- Education: annual infections control and antimicrobial stewardship symposium to educate clinician about appropriate use of antibiotics (ASB topic is not included in the education). In addition, antimicrobial guide is available in the hospital intranet such as clinical practice guideline in emergency department (ED) focus on ASB management where most cases were seen in ED.

- Intravenous (IV) to oral conversion

\section{Data collection}

The data were collected from January 2016 to December 2019. The list of patients who had positive urine culture was obtained from the hospital information systemdatabase. The data collected included age, gender, drug name, dose, frequency, duration, date of treatment start and laboratory results. The criteria for selecting subjects were as follows: hospitalized patients age $\geq 18$ years, with a positive urine culture and no documented signs or symptoms of urinary tract infection. The exclusion criteria included pregnancy, solid organ transplantation, active chemotherapy, and urological surgery.

MDR is defined as microorganisms, predominantly bacteria, that are resistant to one or more classes of antimicrobial agents.

\section{Study outcomes}

This project sought to i) Evaluate the inappropriate use of antibiotics in ASB patients before and after ASP implementation; ii) assess the gaps to reduce the incidence of overtreatment; and iii) identify the type of unnecessarily prescribed antibiotics.

\section{Statistical analysis}

Descriptive included means and standard deviations or percentages asappropriate. Post ASP impleimtation was compared to the standard of care using independent sample t-test for continuous variables and Fisher's exact test for categorical variables.

\section{Result}

A total of 716 patients with a positive urine culture were screened. Among these, we identified 109 patients (15\%) 
with ASB who were included in our study (Fig. 1). The median patient age was 65 years, and common comorbidities included hypertension (82\%), diabetes mellitus melitis (80\%), and dyslipidemia (38\%) (Table 1).

The most important clinically relevant finding was that 95\% $(n=104)$ of ASB patients were inappropriately treated with antibiotics during the study period. Before ASP implementation, the inappropriate use of antibiotic was 96.6\% (53/55) and after ASP was 94.4\% (51/54). Consumption of antibiotic for ASB was 5, 3, 4 and 4 prescriptions per patient-days during the these 4 years. Approximately 71 patients (68\%) were given more than one unnecessary antibiotic either concomitantly or subsequently. Also, $59 \%$ of antibiotics were administered IV, $30.4 \%$ were administered orally (PO) and $10.6 \%$ were converted from IV to PO.

The most commonly used class of antibiotics was cephalosporins (41.2\%), followed by carbapenems (29\%) (Table 2). Of the microorganisms identified in the urine,

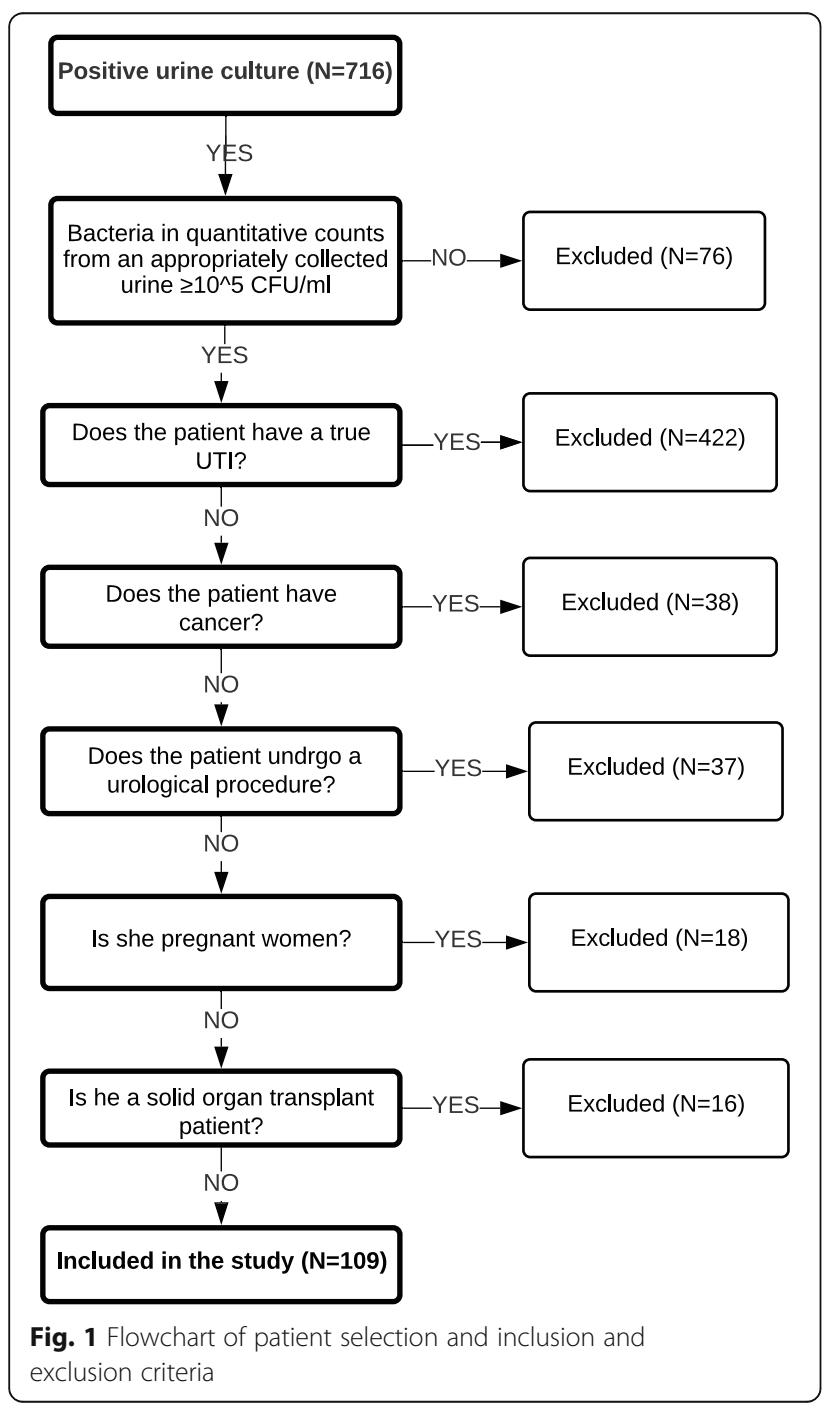

Table 1 Show characteristics of patients diagnosed with asymptomatic bacteriuria (ASB)

\begin{tabular}{|c|c|}
\hline Patient characteristics & Total $(N=109)$ \\
\hline Median age, in years, (range) & $65(11-98)$ \\
\hline Female gender, n (\%) & $74(68)$ \\
\hline Urinary catheter, n (\%) & $64(58.7)$ \\
\hline \multicolumn{2}{|l|}{ Comorbidities } \\
\hline Hypertension, n (\%) & $82(75.2)$ \\
\hline Diabetes mellitus, n (\%) & $80(73.3)$ \\
\hline Dyslipidemia, n (\%) & $38(34.8)$ \\
\hline Ischemic Heart Disease, n (\%) & $37(33.9)$ \\
\hline Neurological disease ${ }^{\mathrm{b}}, \mathrm{n}(\%)$ & $32(29.3)$ \\
\hline Cerebrovascular Accident, n (\%) & $32(29.3)$ \\
\hline Chronic kidney disease, n (\%) & $25(23)$ \\
\hline Endocrine disease ${ }^{c}, \mathrm{n}(\%)$ & $13(11.9)$ \\
\hline Pulmonary disease $^{\mathrm{d}}, \mathrm{n}(\%)$ & $7(6.4)$ \\
\hline \multicolumn{2}{|l|}{ Urinalysis result } \\
\hline Pyuria, n (\%) & $96(88.0)$ \\
\hline $\mathrm{RBCs}^{\mathrm{e}}$ in urine, $\mathrm{n}(\%)$ & $36(33.02)$ \\
\hline Leukocytes in urine, $\mathrm{n}(\%)$ & 100 (91.74) \\
\hline
\end{tabular}

${ }^{\mathrm{a}}$ ASB Asymptomatic Bacteriuria

${ }^{b}$ Neurological disease: Alzheimer's, Parkinson's, Dementia and Epilepsy 'Endocrine disease: Hypothyroidism and Addison's disease

${ }^{\mathrm{d} P u l m o n a r y}$ disease: Asthma and Chronic Obstructive Pulmonary Disease ${ }^{\mathrm{e}} \mathrm{RBCS}$ Red Blood Cell

90.20\% were gram-negative bacteria, of those, $38.7 \%$ were MDR. The numbers of MDR cases from 2016 to 2018 and 2018-2019 were 27 (44\%) and 18 (32\%), respectively (Table 3).

\section{Discussion}

The mismanagement of ASB is a worldwide problem. Treatment of ASB is not only useless but also harmful $[1,3-5,10,11]$. We found that a small number of urine culture order was requested when the patient do not have documented signs and symptoms. This shows that the level of awareness in a physician is high and this practice complies with the stewardship. Implementation of ED antibiotic guideline might have an impact on this result where we found the most ASB cases in ED. Nevertheless, if the culture was requested, almost $95 \%$ of ASB cases were inappropriately treated with antibiotics, a finding that justifies this level of concern, and this percentage remained alarmingly high even after the implementation of ASP. The consumption levels were quite stable at a rate of approximately 4 prescriptions per 1000 patients-days during these 4 years. PAAF was part of the stewardship program; however, the therapeutic intervention was performed during working hours including intervention related to ASB cases. This highlights the importance of $24 \mathrm{~h}$ ASP coverage. Another 
Table 2 Evaluation of antimicrobial agents used, and microorganisms identified in ASB $(N=104)$

\begin{tabular}{ll}
\hline $\begin{array}{l}\text { Number of antimicrobial agents, } \mathrm{n} \\
\text { Ruration, mean }\end{array}$ & 151 \\
Route of administration, $\mathbf{n}(\%)$ & \\
IV & $89(59)$ \\
PO $^{\mathrm{b}}$ & $46(30.4)$ \\
IV to PO & $16(10.6)$
\end{tabular}

Type of antimicrobial agents, $\mathbf{n}(\%)$

\begin{tabular}{ll} 
Quinolones & $29(19.2)$ \\
$\begin{array}{l}\text { B-lactam } \\
\text { Penicillin }\end{array}$ & $73(48.3)$ \\
Cephalosporin & $11(7.28)$ \\
$\quad$ 2nd generation & \\
$\quad$ 3rd generation & $33(21.85)$ \\
Carbapenem & $29(19.21)$ \\
Vancomycin & $44(29.14)$ \\
Others & $1(0.66)$ \\
Microorganisms identified $(\boldsymbol{N}=\mathbf{1 1 6})$ & $4(2.65)$ \\
Gram-positive, $n$ (\%) & \\
Enterococcus & $11(9.40)$ \\
Coagulase negative staph & $7(6.03)$ \\
Streptococcus group B & $2(1.72)$ \\
Gram-negative, $n$ (\%) & $2(1.72)$ \\
E. coli & $105(90.2)$ \\
K. pneumonie & $54(46.55)$ \\
Pseudomonas & $23(19.83)$ \\
Citrobacter & $13(11.21)$ \\
others & $3(2.59)$ \\
\hline
\end{tabular}

${ }^{\mathrm{a}} \mathrm{VV}=$ intravenous; ${ }^{\mathrm{b}} \mathrm{PO}=$ orally

c Multidrug Resistance was 45 (38.7\%) isolates in the urine

alarming result is that the average duration of antimicrobial agents was 12 days. This duration highlights an opportunity for education, not only to avoid antibiotics for ASB, but for true UTIs, cognizance of appropriate duration of therapy.
We found a relatively high proportion of ASB among patients who were female, of advanced age, diabetic, and who had hypertension [12]. This is consistent with findings from other studies $[2,4,7,10]$.

A systematic review and meta-analysis concluded that female gender and the overinterpretation of some laboratory data (positive nitrites, pyuria, presence of gramnegative bacteria and cultures with higher microbial counts) are associated with inappropriate prescribing practices $[4,6]$. In our analysis, we found a similar result.

E. coli, Enterococcus species, and Candida species are common bacterial and fungal colonizers of the urinary tract $[13,14]$. In our analysis, $E$. coli was the most common pathogen associated with ASB, followed by $K$. pneumoniae and Pseudomonas. MDR bacteria are common in our patients ( $44 \%$ vs. $33 \%$ before and after ASP), a finding that could have an impact on the prescribing of antimicrobial agents for ASB.

Cephalosporins was the most frequently used antibiotic class (41\%), followed by carbapenems (29\%) and quinolones. The inappropriate carbapenem prescribing practices might be affected by the high frequency of urine MDR isolates.

The implementation of the ASP was associated with a significant reduction in the use of carbapenems $(P=$ $0.04)$ and an increase in the use of cephalosporins $(P=$ 0.1 ). However, overprescribing antimicrobial agents was a concern in both eras. Since the number of urine culture orders for ASB is considered relatively small number, we aim to identify whom it was ordered by (eg., intern, resident) and when it was ordered (e.g., after working hours) then target those in the stewardship. Furthermore, we plan to embed ASB educational lecture in our annual ASP conference to promote awareness among our healthcare providers and create an ASB protocol. Interestingly, the challenge of managing ASB appropriately may be surmountable with approaches such as identifying the ordering physician, promoting awareness and/or organizational interventions that appear to reduce the incidence of overtreatment.

Table 3 Before and after antimicrobial stewardship program implementation

\begin{tabular}{llll}
\hline & Before ASPs $(\boldsymbol{N}=\mathbf{5 3})$ & After ASPs $(\boldsymbol{N}=\mathbf{5 1})$ & $\boldsymbol{P}$ Value \\
\hline Number of antimicrobial agents per patient & $1.3(73 / 53)$ & $1.5(78 / 51)$ & NA \\
MDR, $\mathrm{n}(\%)$ & $27 / 61(44 \%)$ & $18 / 55(32.7 \%)$ & 0.20 \\
Antimicrobial agents, $\mathbf{n}(\%)$ & & & \\
$\quad$ Carbapenem & $27 / 73(40 \%)$ & $17 / 78(21.8 \%)$ & 0.04 \\
Cephalosporin & $25 / 61(37 \%)$ & $37 / 78(47.4 \%)$ & 0.09 \\
$\quad$ Quinolones & $15 / 61(20.5 \%)$ & $14 / 78(18 \%)$ & 0.68 \\
\hline
\end{tabular}

ASPS Antimicrobial Stewardship MDR Multi-drug Resistance 
The current study has some limitations. First, it was conducted in a single center with convenience sampling which may limit the generalizability of the findings.

\section{Conclusion}

The rate of inappropriate use of antibiotics in ASB is high in ordered urine culture. Targeting asymptomatic bacteruria management in ASP might decrease the misuse of antibiotic, and we should focus on advocating awareness among healthcare providers and implementing stricter protocols.

\section{Abbreviations \\ CFU: Colony-forming units; IDSA: Infectious Diseases Society of America; ASB: Asymptomatic Bacteruria; ASP: Antimicrobial Stewardship Program; MDR: Multidrug-resistant}

\section{Acknowledgements}

We would like to thank the Antimicrobial Stewardship team at Security Forces Hospital for providing the educational materials and related information.

\section{Authors' contributions}

Conceptualization, AAlgh, MA; Data curation, RA, AA, SA, SAl; Project administration, AAlgh, MA; Writing - original draft, GA, IA; Writing - review \& editing, AAlgh. All authors have read and agreed to the published version of the manuscript.

\section{Funding}

This research is funded by the Deanship of Scientific Research at Princess Nourah bint Abdulrahman University through the Fast-track Research Funding Program.

\section{Availability of data and materials}

The data relating to this study are available from the corresponding author upon reasonable request.

\section{Declarations}

\section{Ethics approval and consent to participate}

The study was conducted according to the guidelines of the Declaration of Helsinki, and approved by Security Forces Hospital Institutional Review Board.

\section{Consent for publication}

Not applicable.

\section{Competing interests}

The authors declare no conflict of interest. The funder had no role in the design of the study; in the collection, analyses, or interpretation of data; in the writing of the manuscript, or in the decision to publish the results.

\section{Author details}

${ }^{1}$ Pharmacy Practice Department, Princess Nourah Bint Abdulrahman University, Riyadh, Saudi Arabia. ${ }^{2}$ Pharmacy Practice Department, King Abdullah bin AbdulAziz University Hospital, Riyadh, Saudi Arabia. ${ }^{3}$ Department of Pharmacy, Security Forces Hospital Program, Riyadh, Saudi Arabia. ${ }^{4}$ College of Pharmacy, Princess Nourah Bint Abdulrahman University, Riyadh, Saudi Arabia. ${ }^{5}$ College of Medicine, Imam Mohammed Ibn Saud Islamic University, Riyadh, Saudi Arabia.

Received: 22 May 2021 Accepted: 21 July 2021

Published online: 25 August 2021

\section{References}

1. Nicolle LE, Gupta K, Bradley SF, Colgan R, DeMuri GP, Drekonja D, et al. Clinical practice guideline for the management of asymptomatic bacteriuria: 2019 update by the Infectious Diseases Society of America. Clin Infect Dis. 2019;68(10):E83-75. https://doi.org/10.1093/cid/ciy1121.
2. Lee MJ, Kim M, Kim NH, Kim CJ, Song KH, Choe PG, et al. Why is asymptomatic bacteriuria overtreated?: a tertiary care institutional survey of resident physicians. BMC Infect Dis. 2015;15(1):1-7. https://doi.org/10.1186/ s12879-015-1044-3.

3. Nicolle LE. The paradigm shift to non-treatment of asymptomatic bacteriuria. Pathogens. 2016;5(2):2-7. https://doi.org/10.3390/pathogens502 0038

4. Petty LA, Vaughn VM, Flanders SA, Malani AN, Conlon A, Kaye KS, et al. Risk factors and outcomes associated with treatment of asymptomatic bacteriuria in hospitalized patients. JAMA Intern Med. 2019;179(11):1519-27. https://doi.org/10.1001/jamainternmed.2019.2871.

5. Cai T, Nesi G, Mazzoli S, Meacci F, Lanzafame P, Caciagli P, et al Asymptomatic bacteriuria treatment is associated with a higher prevalence of antibiotic resistant strains in women with urinary tract infections. Clin Infect Dis. 2015;61(11):1655-61. https://doi.org/10.1093/cid/civ696.

6. Flokas ME, Andreatos N, Alevizakos M, Kalbasi A, Onur P, Mylonakis E. Inappropriate Management of Asymptomatic Patients with Positive Urine Cultures: a systematic review and meta-analysis. Open Forum Infect Dis. 2017;4(4):1-10. https://doi.org/10.1093/ofid/ofx207.

7. Ramos-Castaneda JA, Ruano-Ravina A, Salinas DF, Osorio-Manrique J, Segura-Cardona AM, Lemos-Luengas EV. Factors associated with multidrugresistant bacteria in a cohort of patients with asymptomatic bacteriuria who underwent urological surgery. Am J Infect Control. 2019;47(12):1479-83. https:/doi.org/10.1016/j.ajic.2019.06.005.

8. Chowdhury F, Sarkar K, Branche A, Kim J, Dwek P, Nangit A, et al. Preventing the inappropriate treatment of asymptomatic bacteriuria at a community teaching hospital. J Commun Hosp Intern Med Perspect. 2012; 2(2):17814. https://doi.org/10.3402/jchimp.v2i2.17814.

9. Gross PA, Patel B. Reducing antibiotic overuse: a call for a National Performance Measure for not treating asymptomatic bacteriuria. Clin Infect Dis. 2007:45(10):1335-7. https://doi.org/10.1086/522183.

10. Cai T, Koves B, Johansen TEB. Asymptomatic bacteriuria, to screen or not to screen - and when to treat? Curr Opin Urol. 2017;27(2):107-11. https://doi. org/10.1097/MOU.0000000000000368

11. Cope M, Cevallos ME, Cadle RM, Darouiche RO, Musher DM, Trautner BW. Inappropriate treatment of catheter-associated asymptomatic bacteriuria in a tertiary care hospital. Clin Infect Dis. 2009;48(9):1182-8. https://doi.org/10.1 086/597403.

12. Cai T, Mazzoli S, Mondaini N, Meacci F, Nesi G, D'Elia C, et al. The role of asymptomatic bacteriuria in young women with recurrent urinary tract infections: to treat or not to treat? Clin Infect Dis. 2012;55(6):771-7. https:// doi.org/10.1093/cid/cis534.

13. Crader MF, Leslie SW. Bacteruria. In: StatPearls. Treasure Island: StatPearls Publishing; 2020. [Updated 2019 Nov 7]. Available from: https://www.ncbi. nlm.nih.gov/books/NBK482276/.

14. Kelley D, Aaronson P, Poon E, McCarter YS, Bato B, Jankowski CA. Evaluation of an antimicrobial stewardship approach to minimize overuse of antibiotics in patients with asymptomatic bacteriuria. Infect Contr Hosp Epidemiol. 2014;35(2):193-5. https://doi.org/10.1086/674848.

\section{Publisher's Note}

Springer Nature remains neutral with regard to jurisdictional claims in published maps and institutional affiliations.

Ready to submit your research? Choose BMC and benefit from:

- fast, convenient online submission

- thorough peer review by experienced researchers in your field

- rapid publication on acceptance

- support for research data, including large and complex data types

- gold Open Access which fosters wider collaboration and increased citations

- maximum visibility for your research: over $100 \mathrm{M}$ website views per year

At BMC, research is always in progress.

Learn more biomedcentral.com/submissions 